\title{
Orbital exenteration in 95 cases of primary conjunctival malignant melanoma
}

\author{
A D A Paridaens, A C E McCartney, D C Minassian, J L Hungerford
}

\begin{abstract}
The role of orbital exenteration in the management of malignant melanoma of the conjunctiva has been underexplored. The outcome in 95 patients with this condition, who underwent exenteration as a primary treatment $(n=36)$ or after failure of other treatment $(n=59)$ for early to advanced stages of the disease, was evaluated. The majority of treated cases had multicentric melanomas sited at prognostically unfavourable locations. In the group of tumours with a maximum thickness of $1.0 \mathrm{~mm}$ no melanoma related mortality was noted. Melanomas thicker than $1.0 \mathrm{~mm}$ were associated with a mortality varying between $33 \%$ and $50 \%$, independent of whether exenteration was performed as primary or secondary treatment. An especially poor outcome was noted for the group of caruncular melanomas despite exenteration. These findings indicate that total eradication of tumour should be performed at an early stage. For this purpose, a combination of debulking surgery and adjunctive cryotherapy or $\beta$ radiotherapy is more appropriate than orbital exenteration which causes disfigurement and blindness. Exenteration of the orbit should be reserved as a palliative procedure for advanced stages of neoplastic disease.
\end{abstract}

(BrF Ophthalmol 1994; 78: 520-528)

We present a retrospective clinicopathological study of 95 patients with primary conjunctival malignant melanoma who were treated by orbital exenteration between 1948 and 1991. The role of orbital exenteration in the management of malignant melanoma of the conjunctiva remains controversial. ${ }^{1-5}$ This radical surgical procedure consists of removal of the orbital contents, including the globe, the extraocular muscles, orbital fat, the optic nerve, the conjunctival sac and (part of) the eyelids. ${ }^{6}$ It has been used to eradicate various neoplasms, including squamous cell carcinoma, basal cell carcinoma, sebaceous carcinoma, and melanoma of the conjunctiva, ${ }^{7-12}$ usually after failure of other treatments.

Reese recommended exenteration of the orbit for diffuse conjunctival melanomas to eradicate neoplastic tissue completely and to prevent local recurrence.' However, ophthalmic surgeons have been reluctant to perform the operation since exenteration is disfiguring and causes blindness. Fatal outcome despite exenteration is not uncommon and, paradoxically, cure has been observed in cases that were managed by conservative modes of treatment. The rarity and the unpredictable clinical behaviour of malignant melanoma of the conjunctiva have under- mined attempts to investigate scientifically various treatment options, including orbital exenteration, ${ }^{1314}$ in large series.

The aim of this study was to evaluate the effect of orbital exenteration on the outcome of patients suffering from conjunctival melanoma at different stages of the disease. Three case reports are used to illustrate arguments in support of and against orbital exenteration for conjunctival malignant melanoma.

Patients, materials, and methods

Clinicopathological data of individuals who underwent orbital exenteration for primary conjunctival melanoma were retrieved from a database of 256 consecutive patients who were treated in the ocular oncology clinics of Moorfields Eye Hospital and St Bartholomew's Hospital between 1948 and 1991. A risk factor analysis for this population of patients is reported elsewhere. ${ }^{15}$ The following information was obtained for each case: the site of the lesion, the tumour cell type, and the histological precursor lesion (naevus, primary acquired melanosis (PAM), ${ }^{16}$ or none (de novo)). The initial maximum tumour thickness and the maximum tumour thickness of the thickest tumour throughout the follow up period were assessed using semiautomatic computerised image analysis. Lymphatic invasion and tumour invasion into sclera, cornea, tarsal plate, extraocular muscle, and lacrimal apparatus were documented.

The following clinical follow up information was obtained for each patient: date of diagnosis; clinical origin (naevus, PAM, de novo); multifocality; location of the melanoma (cornea, limbus, bulbar, palpebral, or forniceal conjunctiva, caruncle, plica, skin of the eyelids); number of treatments before being seen at the oncology clinics; type of treatment at either hospital; years to the first recurrence; location of recurrence; secondary treatment; interval between diagnosis and exenteration; interval between diagnosis and last date of follow up; interval between exenteration and last date of follow up; outcome; cause of death; and location of metastases (orbit, nasal cavity, or paranasal sinuses, regional lymph nodes, distant sites).

In Moorfields Eye Hospital and St Bartholomew's Hospital orbital exenteration has been advised for extensive diffuse conjunctival melanomas; for unresectable bulky tumours; for melanomas involving the palpebral conjunctiva, fornices, eyelid margin, and caruncle, and when attempts to control the tumour by local treatments fail. Orbital exenteration has been performed rarely when there is evidence of metastatic disease; in the very old; or when the 
Figure 1 Exenteration specimen of a 39-year-old man, consisting of the orbital connective tissues and both eyelids. There is a large pigmented conjunctival melanoma, which is composed of small epithelioid cells and contains a large number of mitotic figures. Note the absence of the globe which was removed in early childhood for unknown reason (haematoxylin and eosin, $\times 3 \cdot 4)$

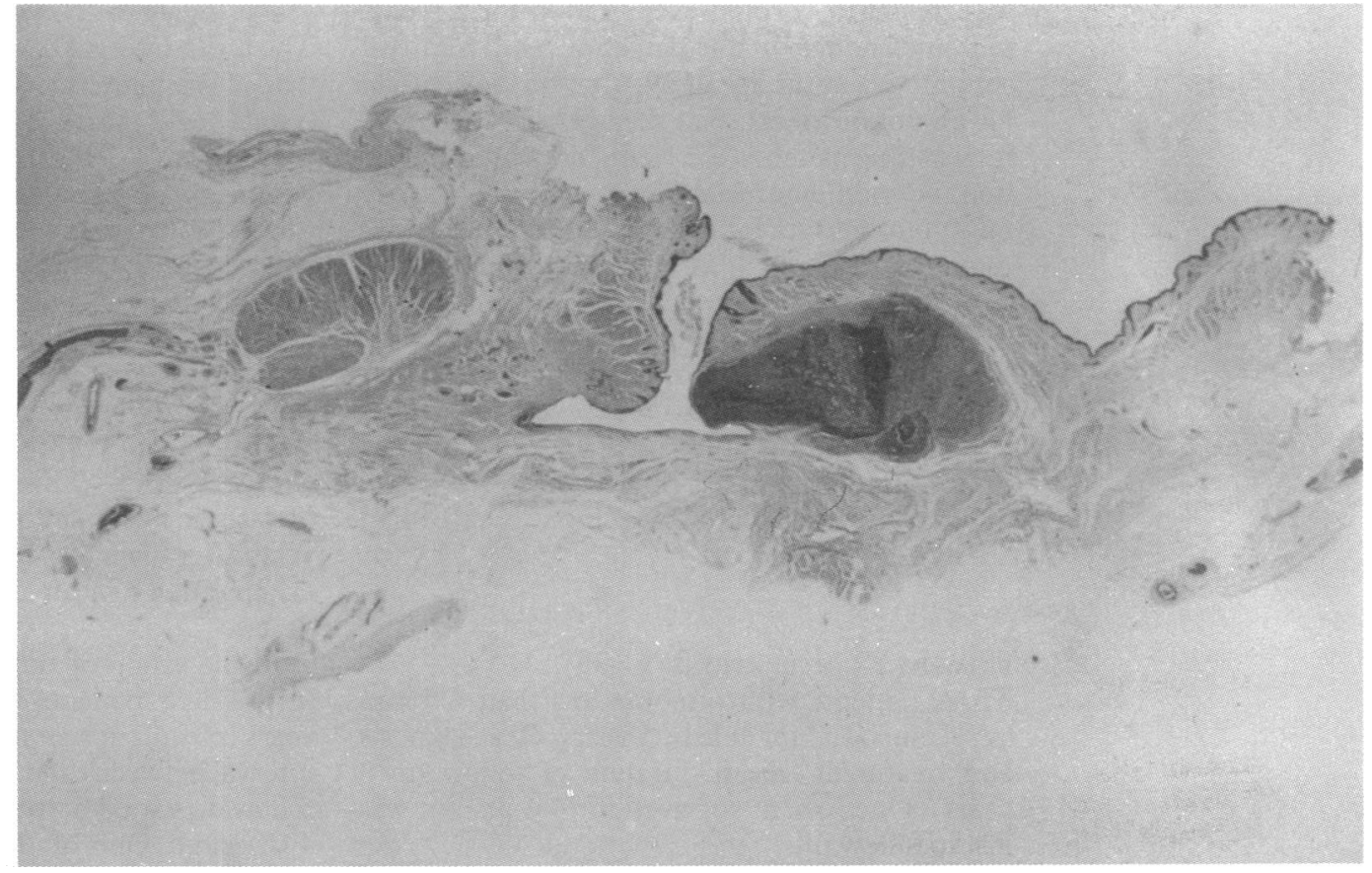

affected orbit contains the only seeing eye. In addition, some patients have refused this mutilating operation. We usually perform an anterior, subtotal lid splitting exenteration, consisting of 'en bloc' excision of the eyelid margins, conjunctival sac, globe, and anterior orbital contents, including ocular muscles, optic nerve, and orbital fat. The remaining eyelid skin is then sutured to line the socket. The lids are removed when there is either flat intraepithelial or frank invasive melanoma involving the eyelids.

The term 'primary exenteration' refers to the implementation of this operation within a short time interval after a formal diagnostic biopsy, while 'secondary exenteration' is performed after failure of earlier conservative treatment. The effect of both primary and secondary orbital exenteration on the outcome was analysed and the mean intervals between exenteration and death were calculated. The patients were classified in groups according to the maximum tumour thickness measured in biopsy or exenteration specimens. Since the majority of melanomas $(>90 \%)$ involved prognostically unfavourable locations at the time of exenteration ${ }^{15}$ and most were multicentric in nature, further subdivision according to location and multifocality was not performed. The melanoma related mortality after exenteration was calculated by dividing the number of patients who died of melanoma by the total of both the patients who survived for at least 5 years and those who died of metastatic disease. For this calculation we excluded patients who were lost to follow up within 5 years - for example, the patients who died of other causes than malignant melanoma of the conjunctiva. Also, we excluded patients with evidence of metastasis at the time of exenteration and patients who underwent exenteration for a painful blind eye following earlier treatment. A separate analysis was performed to evaluate the outcome of patients with caruncular melanomas following exenteration.

Finally, the significance of histological features of exenteration specimens, including the presence of scleral invasion, lymphatic invasion, orbital involvement, and completeness of tumour resection with regard to clinical outcome, was assessed.

\section{Results}

Ninety five (37\%) of 256 patients with invasive malignant melanoma of the conjunctiva ultimately underwent exenteration of the affected $(60 \%)$ were female. The average age at diagnosis was 57.7 years, the youngest patient being 20 and the oldest 92 . Thirty six patients were treated by orbital exenteration as a primary procedure and 59 patients underwent exenteration after treatment failure. The interval between diagnosis and exenteration was 0.4 years (mean value) for the first group and 5.7 years for the latter group. In these $5 \cdot 7$ years, a mean of $2 \cdot 2$ excision biopsies were performed with adjunctive cryotherapy or radiotherapy in a limited number of cases.

Two individuals underwent exenteration of the orbit following earlier enucleation in 1962 and 1965 respectively. One of them developed multifocal melanoma in the remaining conjunctiva 7 years after enucleation for a small melanoma sited at the corneal limbus. The other

Table 1 Outcome of 95 patients following orbital exenteration

\begin{tabular}{|c|c|c|c|c|}
\hline \multirow{2}{*}{$\begin{array}{l}\text { Maximum } \\
\text { thickness }\end{array}$} & \multirow{2}{*}{$\begin{array}{l}\text { Survival } \\
\text { follow up } \\
<5 \text { years }\end{array}$} & \multirow{2}{*}{$\begin{array}{l}\text { Survival } \\
\text { follow up } \\
>5 \text { years }\end{array}$} & \multicolumn{2}{|c|}{ Melanoma related death } \\
\hline & & & $<5$ years & $>5$ years \\
\hline $\begin{array}{c}<1 \mathrm{~mm} \\
(\mathrm{P}, \mathrm{n}=4) \\
(\mathrm{S}, \mathrm{n}=3) \\
1-2 \mathrm{~mm}\end{array}$ & $\begin{array}{l}P, n=1 \\
S, n=1\end{array}$ & $\begin{array}{l}P, n=3 \\
S, n=2\end{array}$ & $\begin{array}{l}P, n=0 \\
S, n=0\end{array}$ & $\begin{array}{l}P, n=0 \\
S, n=0\end{array}$ \\
\hline $\begin{array}{c}(\mathrm{P}, \mathrm{n}=8) \\
(\mathrm{S}, \mathrm{n}=12) \\
>2 \mathrm{~mm}\end{array}$ & $\begin{array}{l}P, n=1 \\
S, n=2\end{array}$ & $\begin{array}{l}P, n=4 \\
S, n=7\end{array}$ & $\begin{array}{l}P, n=3 \\
S, n=0\end{array}$ & $\begin{array}{l}\mathrm{P}, \mathrm{n}=0 \\
\mathrm{~S}, \mathrm{n}=3\end{array}$ \\
\hline $\begin{array}{l}(P, n=24) \\
(S, n=44)\end{array}$ & $\begin{array}{l}P, n=4 \\
S, n=8\end{array}$ & $\begin{array}{l}P, n=10 \\
S, n=18\end{array}$ & $\begin{array}{l}\mathrm{P}, \mathrm{n}=10 \\
\mathrm{~S}, \mathrm{n}=7\end{array}$ & $\begin{array}{l}P, n=0 \\
S, n=11\end{array}$ \\
\hline
\end{tabular}

Primary exenteration $(\mathbf{P})(\mathrm{n}=36)$ and secondary exenteration $(\mathrm{S})$ $(n=59)$. orbit. Thirty eight $(40 \%)$ patients were male, 57 
was treated by orbital exenteration for a recurrent melanoma of the palpebral and forniceal conjunctiva at the age of 39 , after an enucleation for an unknown cause at the age of 3 (Fig 1). A total of nine patients $(9.5 \%)$ underwent exenteration for epibulbar melanomas: three for primary melanoma and six for recurrent tumours. One of those patients died as a result of metastatic disease.

Table 1 displays the outcome of patients, who were divided into groups according to whether exenteration was performed as a primary or a secondary procedure and to whether the maximum tumour thickness was less than $1.0 \mathrm{~mm}$, between 1.0 and $2.0 \mathrm{~mm}$, or exceeding $2.0 \mathrm{~mm}$.

\section{PRIMARY EXENTERATIONS $(\mathbf{n}=36)$}

Three patients with tumours less than $1.0 \mathrm{~mm}$ $(n=4)$ survived for at least 5 years after diagnosis and treatment (mean duration of follow up 8 years). One patient survived for 3 years but was lost to follow up.

In the group of patients with tumours between 1 and $2 \mathrm{~mm}$ in thickness $(\mathrm{n}=8)$, four survived for at least 5 years (mean duration of follow up 9 years). Another patient survived 2 years but died of another cause. Three patients developed metastatic melanoma, all dying within 5 years of diagnosis and orbital exenteration (mean $2 \cdot 2$ years, range 1.5-3.0 years). In the group of patients with tumours more than $2 \mathrm{~mm}(\mathrm{n}=24)$ 10 survived at least 5 years (mean duration of follow up 8 years), while 10 patients suffered melanoma related death within 5 years. In one patient who died, there was cancerous preauricular lymph node involvement at the time of exenteration. Four other patients were lost to follow up within 5 years, two of whom died: one died of 'peritonitis' 2 years after exenteration, another died of unrelated cause 4 years after exenteration.

The melanoma related mortality following primary exenteration and the mean interval between orbital exenteration and death for different categories classified according to maximum tumour thickness are shown in Table 2.

\section{SECONDARY EXENTERATIONS}

Two patients with tumours less than $1.0 \mathrm{~mm}$ $(\mathbf{n}=3)$ survived for 25 and 30 years after diagnosis and 6 and 27 years after exenteration. One patient survived for 4 years after diagnosis and 1 year after exenteration but was lost to follow up.

In the category of melanomas with a thickness between 1.0 and $2.0 \mathrm{~mm}(\mathrm{n}=12)$, seven patients $(58 \%)$ survived for at least 5 years (mean $10 \cdot 6$

Table 2 Melanoma related mortality within 5 years of exenteration

\begin{tabular}{|c|c|c|c|c|}
\hline $\begin{array}{l}\text { Maximum } \\
\text { thickness }\end{array}$ & $\begin{array}{l}\text { Primary } \\
\text { exenteration } \\
(\%)(n=29)^{\star}\end{array}$ & $\begin{array}{l}\text { Mean interval between } \\
\text { exenteration and death } \\
\text { (years) }\end{array}$ & $\begin{array}{l}\text { Secondary } \\
\text { exenteration } \\
(\%)(n=45)^{\star}\end{array}$ & $\begin{array}{l}\text { Mean interval } \\
\text { between exenteration } \\
\text { and death (years) }\end{array}$ \\
\hline $\begin{array}{l}<1 \mathrm{~mm} \\
>1-2 \mathrm{~mm} \\
>2 \mathrm{~mm}\end{array}$ & $\begin{array}{l}0 \cdot 0(n=3) \\
43(n=7) \\
47(n=19)\end{array}$ & $\begin{array}{l}\overline{2} \cdot 2 \\
2 \cdot 2\end{array}$ & $\begin{array}{l}0 \cdot 0(n=2) \\
33(n=9) \\
50(n=34)\end{array}$ & $\begin{array}{l}\overline{2} \cdot 2 \\
2 \cdot 1\end{array}$ \\
\hline
\end{tabular}

^Only a selection of patients was included in the calculation of the melanoma related mortality (inclusion criteria - see text). years; range 6-21 years) following diagnosis. The mean interval between exenteration and the date of last follow up of those seven was 4.8 years (range 1-12 years). One patient developed a biopsy proved regional lymph node metastasis within 2 years of orbital exenteration, which was treated by excision and radiation therapy. He has subsequently remained free from disease. Another patient underwent exenteration of the orbit because of a painful blind eye following earlier treatment with heavy irradiation for conjunctival melanoma.

Two patients (17\%) died of unrelated disease within 5 years. Three patients $(25 \%)$ died of metastatic malignant melanoma, all more than 5 years after diagnosis but within 3 years of orbital exenteration (mean 2.2 years; range $0.5-3.0$ years).

In the group of tumours larger than $2.0 \mathrm{~mm}$ $(n=44), 18$ patients $(41 \%)$ survived at least 5 years (mean $7 \cdot 6$ years; range $5 \cdot 0-25$ years). The interval between exenteration and the end date of follow up varied between 1.0 and 12 years (mean 4.6 years). One of those patients required an orbital exenteration for a painful blind eye following earlier radiation treatment and another developed a nasal metastasis which was locally excised. Eight patients (18\%) were lost to follow up: three died of unrelated cause while five were not seen again in our clinics nor was information available from their general practitioner. Seven (16\%) died within 5 years of diagnosis and within 3 years of exenteration (mean 1.6 years; range $0.5-3.0$ years), one of whom had evidence of ipsilateral lymph node enlargement at the time of exenteration. Eleven patients $(26 \%)$ died at least 5 years after diagnosis but within 5 years of exenteration (mean 2.5 years; range $1 \cdot 0-5 \cdot 0$ years).

\section{MELANOMA RELATED MORTALITY}

Table 2 shows the melanoma related mortality of patients who underwent orbital exenteration for conjunctival melanoma in relation to tumour thickness. For this calculation, seven patients were excluded from the group of primary exenterations, while 14 were excluded from the group of secondary exenterations for various reasons, mentioned above. There was no mortality due to metastatic melanoma in the first category of tumours smaller than $1.0 \mathrm{~mm}$. The differences in mortality between the group of patients who underwent orbital exenteration as a primary procedure and those who required this treatment after earlier failure of conservative management are not significant $\left(\chi^{2}\right.$ test, $\mathrm{p}>0.05)$. Although it appears to be a trend for melanomas thicker than $2.0 \mathrm{~mm}$ to be associated with a worse outcome than tumours measuring between 1.0 and $2.0 \mathrm{~mm}$, there is no significant difference $(p>0.05)$. The intervals between exenteration and metastatic death are similar for all groups.

CARUNCULAR MELANOMAS AND OUTCOME FOLLOWING EXENTERATION

Table 3 shows the outcome following orbital exenteration in 18 cases of malignant melanoma 
Table 3 Caruncular melanomas and outcome following exenteration

\begin{tabular}{|c|c|c|c|c|c|c|c|}
\hline $\begin{array}{l}\text { Patient } \\
\text { No }\end{array}$ & Location * & $\begin{array}{l}\text { Max } \\
\text { thickness } \\
\text { (mm) }\end{array}$ & $P / S t$ & Cell typeł & $\begin{array}{l}\text { Follow up } \\
\text { (years)s }\end{array}$ & Death & $\begin{array}{l}\text { Interval between } \\
\text { exenteration and } \\
\text { death (years) }\end{array}$ \\
\hline $\begin{array}{r}1 \\
2 \\
3 \\
4 \\
5 \\
6 \\
7 \\
8 \\
9 \\
10 \\
11 \\
12 \\
13 \\
14 \\
15 \\
16 \\
17 \\
18\end{array}$ & $\begin{array}{l}4,6,7 \\
2-9 \\
3-9 \\
2-4,7 \star \star \\
5,6,7,9 \\
5,6,7,9 \\
6,7,8^{\star \star} \\
4-7 \\
7 \star \star \\
3-8 \\
4,7,8,9 \\
1-8 \\
7,8,9 \star \star \\
4,7 \\
6,7 \star \star \\
7 \star \star \\
7 \star \star \\
4-7\end{array}$ & $\begin{array}{c}0.8 \\
0.32 \\
1.8 \\
1.0 \\
1.2 \\
1.0 \\
7.0 \\
2.3 \\
5 \\
12 \\
4.0 \\
30.0 \\
3.6 \\
2.0 \\
5.0 \\
3.0 \\
14.0 \\
3.7\end{array}$ & $\begin{array}{l}S \\
S \\
S \\
P \\
S \\
P \\
P \\
P \\
P \\
P \\
S \\
S \\
P \\
S \\
S \\
S \\
S \\
P\end{array}$ & $\begin{array}{l}\mathbf{S}=S \\
\mathbf{S}=S \\
\mathbf{E}>S \\
S>E \\
S \\
E=S \\
E \\
E \\
E>S \\
E \\
E \\
E>S \\
E=S \\
S \\
E \\
E<S \\
E>S\end{array}$ & $\begin{array}{c}30 \\
25 \\
21 \\
4 \cdot 0 \\
6 \cdot 0 \\
16 \\
1 \cdot 0 \\
7 \cdot 0 \\
3 \cdot 0 \\
22 \\
2 \cdot 5 \\
15 \\
3 \cdot 0 \\
5 \cdot 0 \\
3 \cdot 0 \\
3 \cdot 0 \\
18 \\
3 \cdot 0\end{array}$ & $\begin{array}{l}\text { No } \\
\text { No } \\
\text { No } \\
\text { Yes } \\
\text { Yes } \\
\text { No } \\
\text { No } \\
\text { No } \\
\text { Yes } \\
\text { No } \\
\text { Yes } \\
\text { No } \\
\text { Yes } \\
\text { Yes } \\
\text { Yes } \\
\text { Yes } \\
\text { Yes } \\
\text { Yes }\end{array}$ & $\begin{array}{l}- \\
- \\
\overline{3} \\
3.0 \\
3.0 \\
- \\
\overline{-} \\
\overline{3} \cdot 0 \\
\overline{0} \cdot 5 \\
\overline{3} \\
1.0 \\
3.0 \\
2.5 \\
2.0 \\
3.0\end{array}$ \\
\hline
\end{tabular}

$\star 1=$ cornea; $2=$ cornea limbal; 3 = bulbar conjunctiva $<2 \mathrm{~mm}$ of cornea; $4=$ bulbar conjunctiva $>2 \mathrm{~mm}$ of cornea; $5=$ palpebral conjunctiva; $6=$ fornix; $7=$ caruncula; $8=$ plica; $9=$ eyelid.

$+\mathrm{P}=$ primary; $\mathrm{S}=$ secondary.

Follow up from date of histological diagnosis.

$\star \star$ Melanoma predominantly sited at caruncle.
HISTOLOGICAL FEATURES IN EXENTERATION SPECIMENS RELATED TO OUTCOME

\section{Scleral invasion}

In six exenteration specimens, scleral invasion by melanoma was noted (Fig 2). All six tumours were multifocal and all cell types were represented, including spindle, epithelioid and mixed cell type. In all, there was complete resection of melanoma and the maximum tumour thickness was greater than $2.0 \mathrm{~mm}$.

Four patients $(67 \%)$ suffered metastatic death within 1.5 to 3 years of exenteration. In the histological specimen of one of these, tumour invasion into the anterior chamber and a rectus muscle was noted in addition to scleral invasion. In the specimen of another patient who developed preauricular lymph node enlargement and died 3 years after exenteration, a deep orbital tumour nodule was noted. The other two (33\%) individuals survived for at least 14 years without evidence of recurrent disease.

which involved the caruncle. Of this group of tumours, seven melanomas (Table 3 ) were predominantly sited at the caruncle. In the other cases, the malignancy was more multifocal at presentation. Ten out of $18(56 \%)$ patients, one of whom had ipsilateral lymph node involvement at the time of exenteration, died within 3 years of radical surgery. Of the seven patients with predominantly caruncular melanomas, six $(86 \%)$ died, including the patient with lymph node enlargement at exenteration. A fatal outcome was noted both in cases where histological examination of the exenteration specimen had suggested complete resection (for example, case no 13 , Table 3), and those in which residual tumour was suspected (for example, case no 11).

In one case (case no 24) recurrent disease was noted in the nose and orbit 21 years after exenteration. ${ }^{17}$

\section{Lymphatic invasion}

Lymphatic invasion as a histological feature was noted in specimens of 16 patients who underwent orbital exenteration. In this group all melanomas were multifocal and involved prognostically adverse sites. One tumour was smaller than $1 \mathrm{~mm}$, seven measured between 1 and $2 \mathrm{~mm}$, and the other eight melanomas were larger than $2 \mathrm{~mm}$.

In $11(69 \%)$ of 16 patients the tumour recurred, leading to metastatic death in eight patients. One of the 16 patients had a local recurrent melanoma in the orbit within 3 years of exenteration, which was excised. Two patients experienced lymph node recurrences in the regional glands; in the exenteration specimen of one of those, there was deep tumour spread near the canaliculi (see case report 3 ).
Figure 2 Deep (black arrow) and superficial (open arrow) scleral invasion of malignant melanoma of the bulbar and limbal conjunctiva and the cornea (haematoxylin and eosin, $\times 54)$.

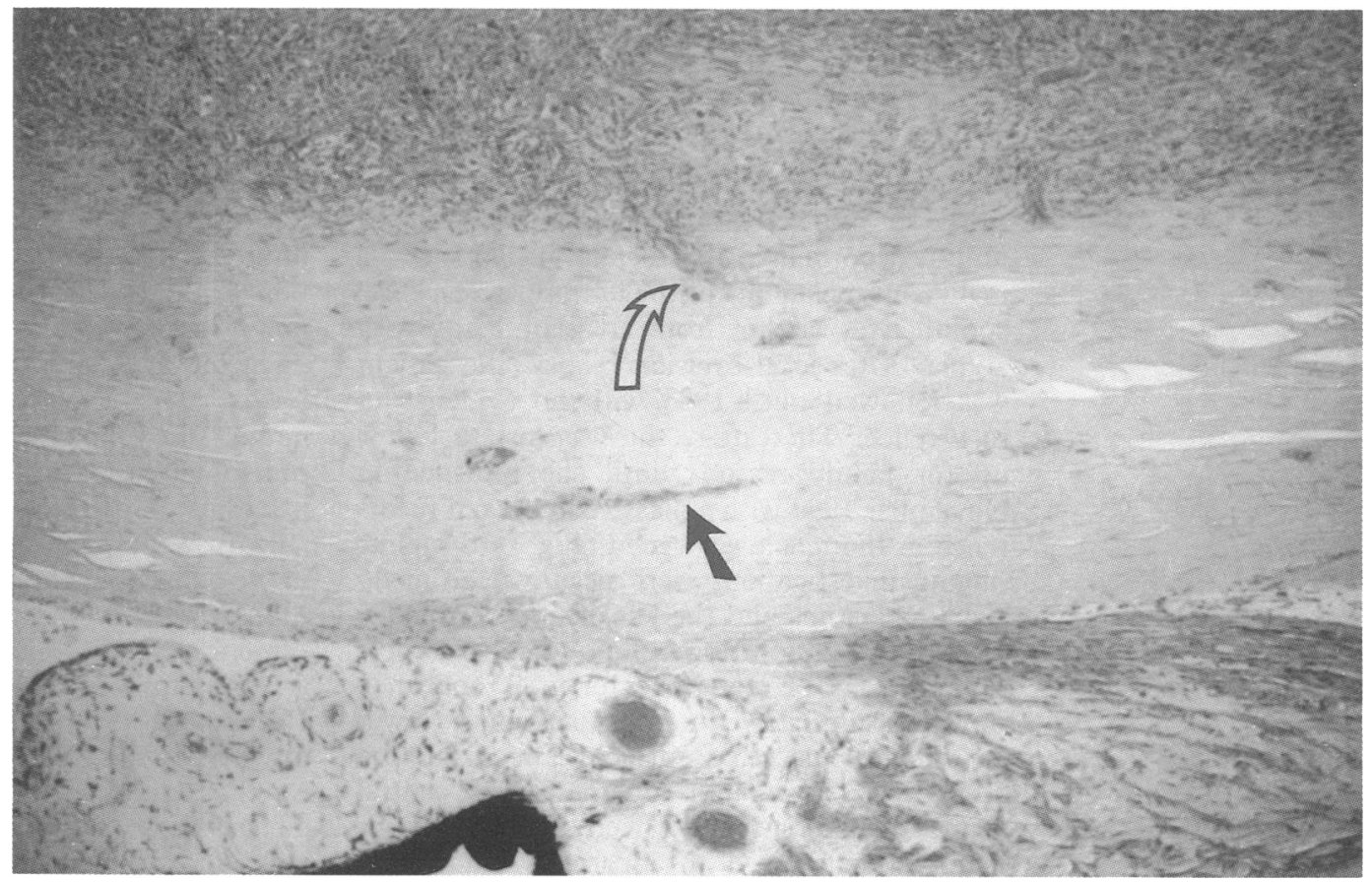




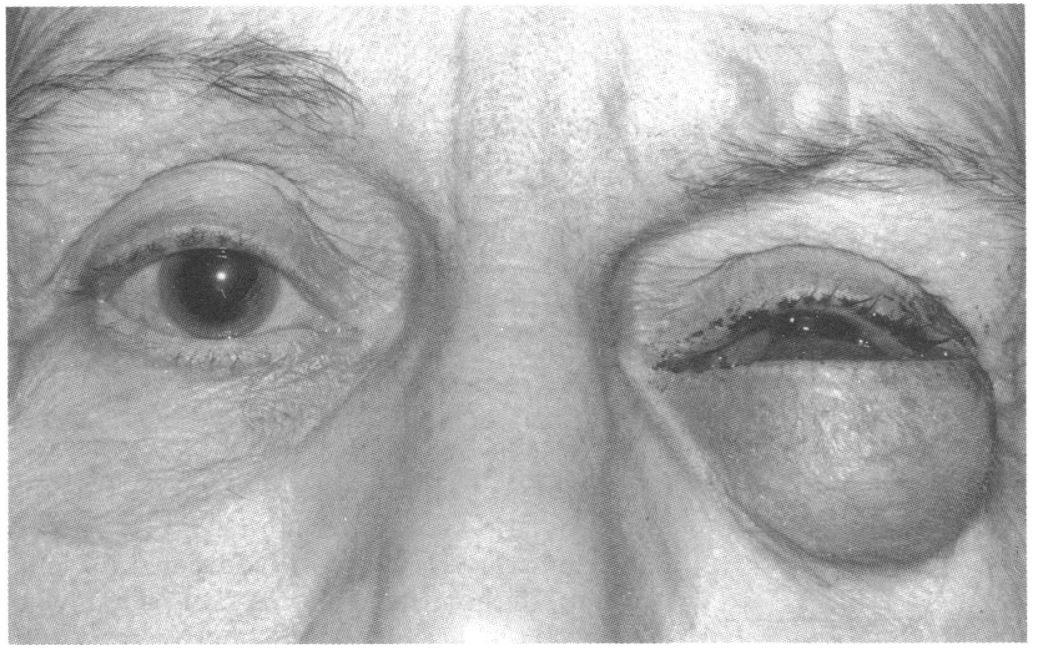

Figure 3 A 61-year-old woman with a massive recurrence of conjunctival malignant melanoma in the left lower eyelid (case report 1).

Completeness of tumour resection and outcome

Eight cases were identified where histological examination of the exenteration specimen suggested incomplete resection of the malignant melanoma. Two patients had been treated by primary exenteration, the other six patients had had exenteration after several (between two and six) excision biopsies. Two of eight cases showed no evidence of local or distant recurrent melanoma on 5 year follow up, despite the fact that the margins of the exenteration specimen were not free of tumour and residual melanoma was suspected. One of those patients died of an unrelated cause 7 years after exenteration. Three patients suffered metastatic death without evidence of local recurrent tumour growth within 1 to 4 years of orbital exenteration. Two patients developed regional metastases within 1 year of surgery; one was treated by radical neck dissection and survived until the end of follow up, the other was treated by a combination of local excision and radiotherapy but developed an orbital nodule. After local excision of the tumour recurrence, he died of widespread metastases 1 year after the initial treatment. Another patient experienced recurrent orbital melanoma but has survived at least 4 years following local excision.

\section{Illustrative case reports}

CASE 1 - PALLIATIVE EXENTERATION FOLLOWING AN 8 YEAR DISEASE FREE INTERVAL

A 61-year-old woman presented to the oncology unit at Moorfields Eye Hospital in 1977 with a malignant melanoma of the left upper palpebral conjunctiva, arising from areas of PAM with atypia. After local excision biopsy, the patient was followed until 1985 with no evidence of recurrence. Thereafter, she was lost to follow up for family reasons until she returned in November 1990 with a massive neglected recurrence in the left lower eyelid (Fig 3). Systemic staging investigations were negative for metastatic melanoma and the left orbit was exenterated using a lid splitting technique. Macroscopic examination of the exenteration specimen showed a soft pale yellow solid mass in the lower lid with an ulcerated surface. The maximum dimension was $30 \mathrm{~mm}$ and there were central areas of haemorrhage and necrosis. Microscopic examination showed an apparently completely excised epithelioid malignant melanoma, involving both upper and lower palpebral conjunctiva but not the globe. Seven months later the patient was noted to have a subcutaneous cystic swelling in the left orbit. On palpation, there was a firm swelling in the depth of the orbit. Aspiration cytological examination revealed melanoma cells in both areas. Computed tomography scans of the head and orbits showed extensive neoplastic involvement of the left orbit, the maxillary antrum, the temporal fossa, and the extradural space of the frontal fossa (Fig 4). Restaging disclosed no evidence of distant metastatic disease and the patient, who refused surgery, was referred for neutron therapy.

\section{Comment}

This case illustrates the recurrent nature of melanomas arising from multifocal PAM and the need for treatment of conjunctival areas that show melanosis with cellular atypia upon histological examination, to prevent recurrence. It also demonstrates the necessity for continuous surveillance of neoplastic activity, even after an 8 year disease free interval. The patient should be well informed about the nature of this neoplasm and should have regular visits to the oncology clinic for follow up. Every nodule occurring in an exenterated orbit should be cytologically or histologically explored, even when it mimics an inclusion cyst.

\section{CASE 2 - PRIMARY EXENTERATION OF CARUNCLE} MELANOMA AND FAILURE OF TUMOUR CONTROL In April 1987 a 44-year-old woman presented to a local ophthalmologist with a 2 month history of an itchy right eye and a 12 month history of gradually increasing pigmentation of the right lower lid. On examination she was found to have a brown fleshy mass $(1.2 \times 1.2 \mathrm{~cm})$ with an ulcerated surface extending from the caruncle, with flat pigmentation extending laterally along the lower lid margin (Fig 5). She was then referred to Moorfields Eye Hospital and her tumour was clinically diagnosed as malignant melanoma of the caruncle and skin, which was confirmed by incisional biopsy. Systemic investigations for disseminated melanoma were negative and the right orbit, including the eyelids, was exenterated. Macroscopic examination of the exenteration specimen showed pigmentation of the skin surface of the lower lid and a nodule of greyish tumour with a maximum diameter of $4 \mathrm{~mm}$ in the lower conjunctival fornix. Histological examination showed a nodule of hypopigmented malignant melanoma protruding into the lower fornix rather than invading the subconjunctival connective tissue (Fig 6). Widespread PAM with atypia was noted in the palpebral conjunctiva and adjacent skin of the lower lid, where there was also invasive tumour. All resection margins were apparently free from tumour. The patient was followed until December 1989 without evidence of recurrent disease, but in January 1990 she deteriorated rapidly and a chest $x$ ray showed multiple metastases. A course of radiotherapy had little effect and she died within 3 months. 
Figure 4 Computed tomography $(C T)$ scans showing extensive involvement of the extradural space of the left frontal fossa $(A)$, the left orbit, the temporal fossa $(B)$ and the maxillary antrum

(C) by melanoma (arrows) (case report 1).

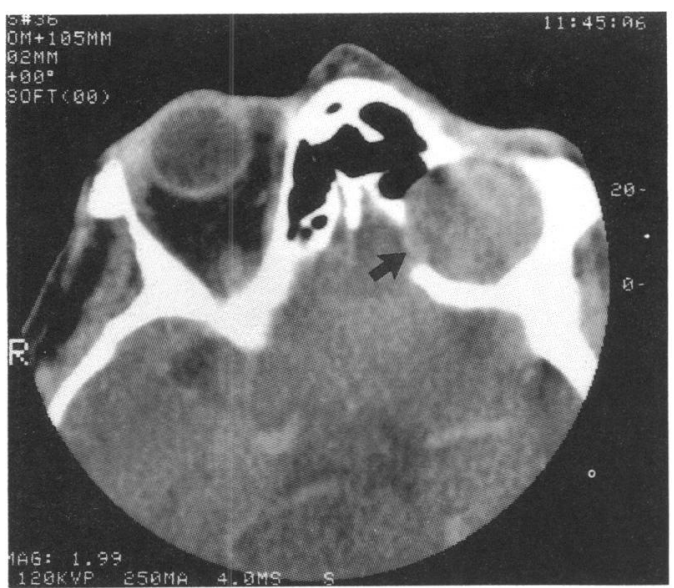

Fig 4 A

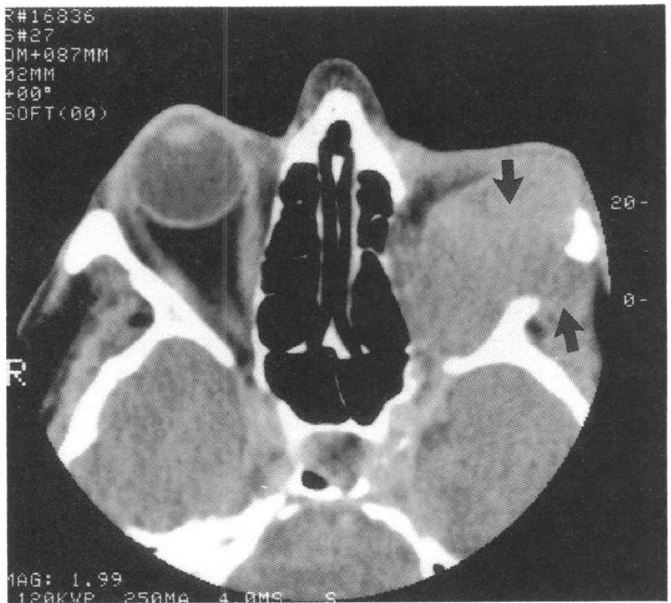

Fig $4 B$

\section{Comment}

This case is an example of the poor outcome which has been observed in patients with caruncular melanoma. Radical surgery with apparent histological excision of the tumour could not prevent distant metastases and subsequent death 3 years after the orbital exenteration.

CASE 3 - ORBITAL SPREAD IN EXENTERATION SPECIMEN AND SUBSEQUENT DEVELOPMENT OF HOMOLATERAL REGIONAL LYMPH NODE METASTASIS

A 52-year-old woman was seen in 1983 with a 10 year history of gradually developing multicentric pigmentation around the right corneal limbus. An inferior limbal raised lesion was treated by excision and cryotherapy. Seven months later, a superior limbal nodule was excised. Histological examination of both biopsies showed incompletely excised superficial spreading conjunctival melanoma arising from PAM. There was no further clinical evidence of malignant melanoma until 1989 when multiple nodules developed in the limbus, bulbar conjunctiva, and inferior fornix. After another two biopsies and a negative systemic metastatic evaluation, the right orbit was exenterated. The exenteration specimen showed multifocal conjunctival malignant melanoma and PAM, with a separate deeper focus of S-100 positive tumour in the connective tissue close to the canaliculi (Fig 7). However,

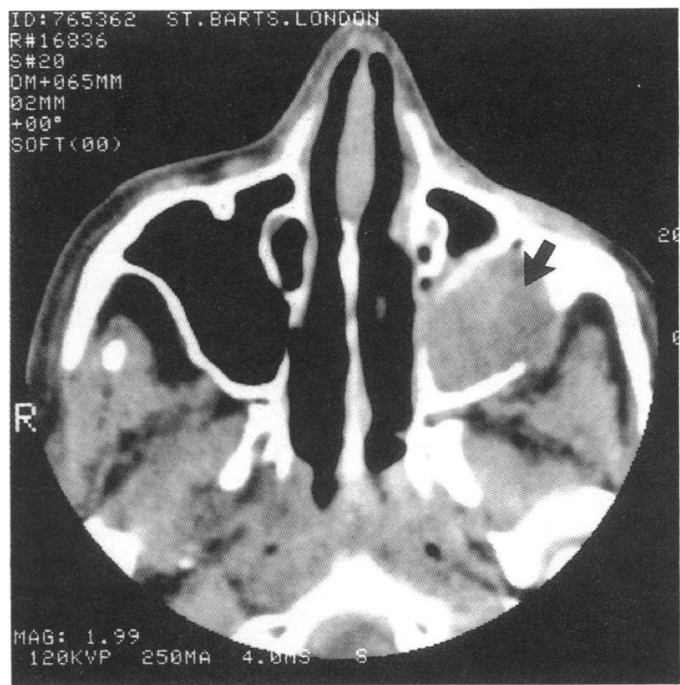

Fig $4 C$

the tissue margins were apparently free from tumour. Eight months following surgery, she represented with an ipsilateral submandibular lymph node recurrence.

\section{Comment}

This case demonstrates the difficulty of conservative management of conjunctival melanoma originating from multicentric PAM, especially when the disease enters an aggressive phase. It is an illustration of the increased risk of metastases when orbital invasion is observed in the exenteration specimen.

\section{Discussion}

The choice of treatment for malignant melanoma of the conjunctiva and the time of its implementation largely depends on the clinical presentation. This may vary from a localised nodular tumour without surrounding pigmentation to diffuse melanoma with multifocal invasive nodules, arising from widespread areas of flat acquired melanosis (primary acquired melanosis $^{16}$ or Reese's precancerous melanosis ${ }^{1}$ ). In 1964 Reese $^{1}$ advocated therapeutic excision for areas of 'precancerous and cancerous melanosis' that are entirely confined to one site, but he believed removal of all potentially diseased conjunctiva by orbital exenteration at a relatively early stage to

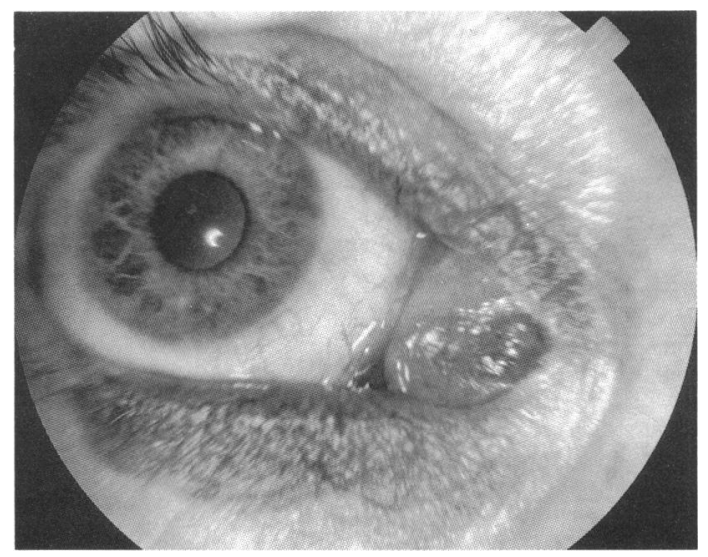

Figure 5 Malignant melanoma $(1 \cdot 2 \times 1 \cdot 2 \mathrm{~cm})$ with an ulcerated surface at the caruncle with flat pigmentation extending laterally along the lower lid margin (case report 2). 
Figure 6 Histological examination of this exenteration specimen showed a nodular malignant melanoma with a maximum diameter of $4 \mathrm{~mm}$ protruding into the lower fornix, and widespread primary acquired melanosis with atypia in the palpebral conjunctiva and adjacent eyelid skin (haematoxylin and eosin, $\times 3 \cdot 4$ ) (case report 2 ).

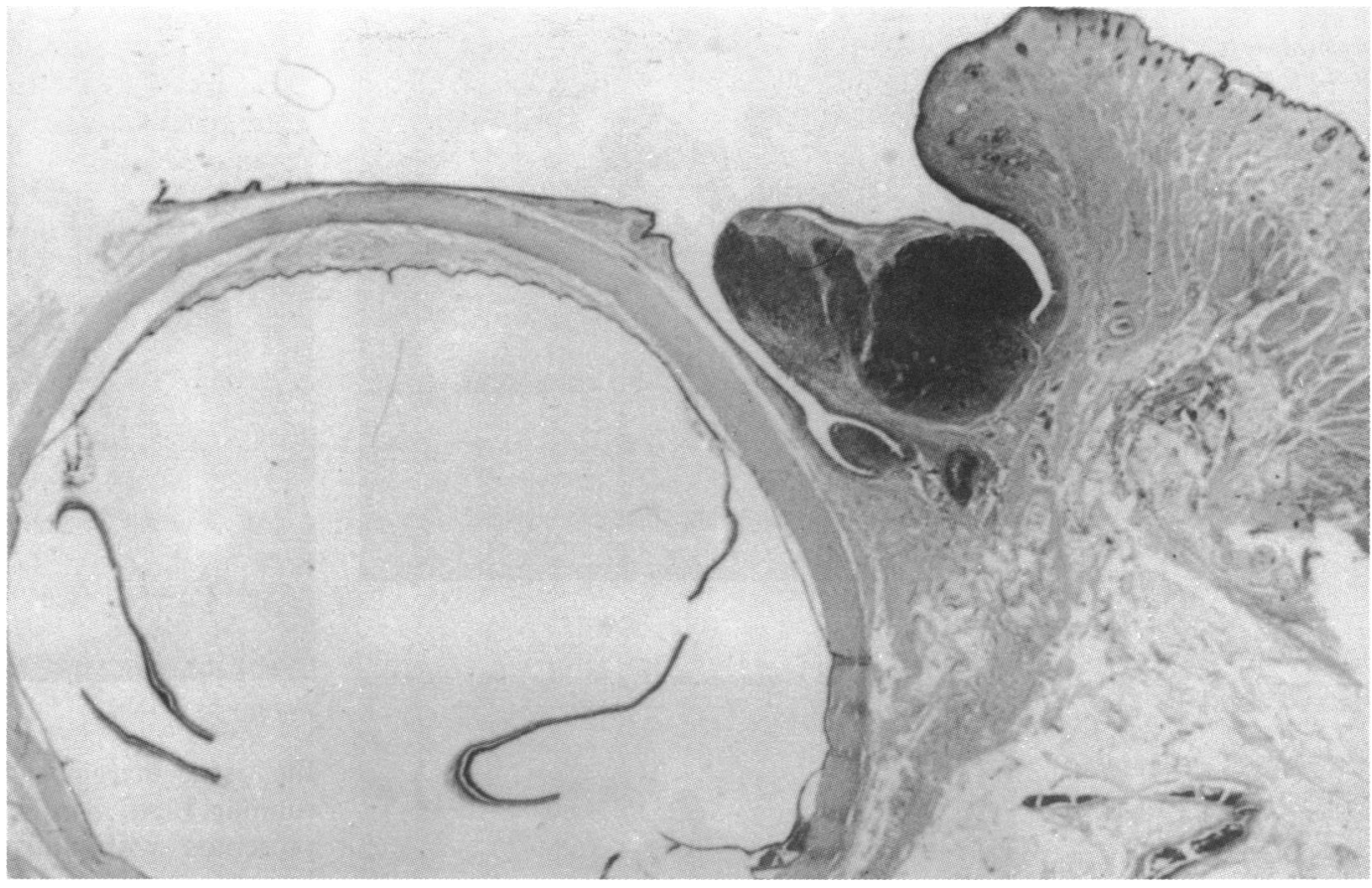

be the only effective treatment for diffuse lesions. In 1964, Zimmerman ${ }^{2}$ argued against the use of the term 'precancerous melanosis' since not all lesions with features of acquired melanosis have a tendency to progress to invasive melanoma, and thus prevented surgeons from performing radical surgery for benign conditions of the conjunctiva. This was supported by Folberg and co-workers ${ }^{18}$ who showed that in their series of 41 cases of primary acquired melanosis, none of the 13 cases of PAM without atypia progressed to invasive melanoma, while $13(46 \cdot 4 \%)$ of the 28 lesions of PAM with atypia eventually evolved into malignant melanoma.

Silvers and colleagues ${ }^{14}$ showed that invasive conjunctival melanomas with a thickness less than $1.5 \mathrm{~mm}$ were associated with a favourable prognosis regardless of whether the lesions were treated by excision biopsy or exenteration of the

orbit. Furthermore, these authors noted the absence of a beneficial effect on survival of orbital exenteration for melanomas measuring more than $2.0 \mathrm{~mm}$. In the present study this phenomenon was observed for tumours thicker than $1.0 \mathrm{~mm}$, regardless of whether exenteration was performed as a primary or a secondary procedure. We also noted a high melanoma related mortality varying between 33 and $50 \%$ for melanomas thicker than $1.0 \mathrm{~mm}$ despite exenteration. These findings suggest that tumour cells had spread to distant sites before surgery and that metastasis is related to the invasive stage.

Several factors have been identified which influence the course of the disease and outcome of the patient suffering from malignant melanoma of the conjunctiva, including the tumour thickness, the cell type and mitotic
Figure 7 A separate nodus of $S-100$ positive melanoma (large arrow) in the connective tissue on the medial aspect of the

exenteration specimen close to the canaliculi, which are filled with erythrocytes (small arrow). There is a marked inflammatory response and zone of necrosis

(haematoxylin and eosin

$\times 100)($ case report 3$)$.

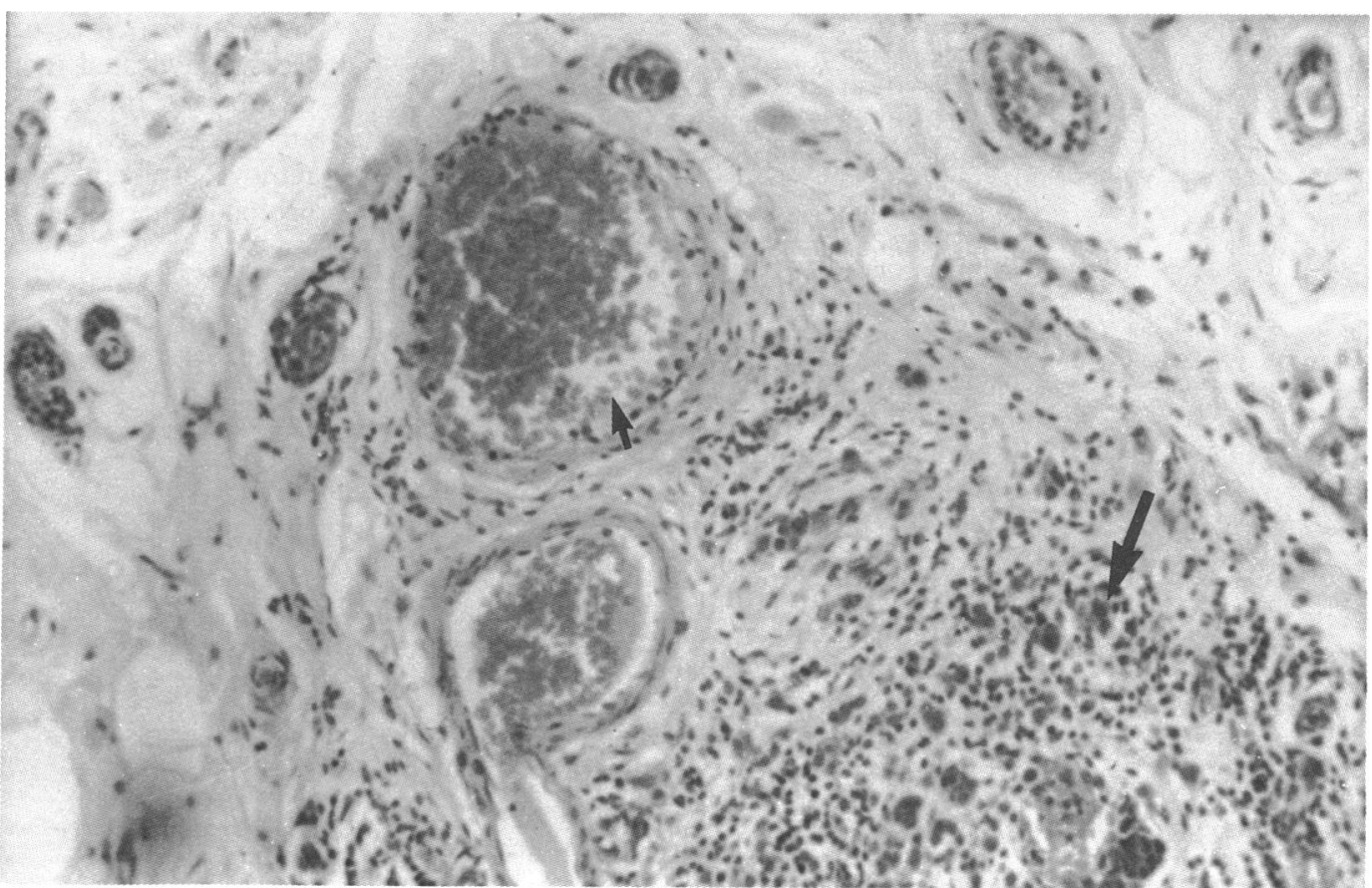


activity, lymphatic invasion, and the location within the conjunctiva. ${ }^{15}{ }^{19-21}$ Other factors that may influence the risk of metastasis include the area of invasive tumour and the time interval between cellular invasion of the subepithelial space and surgical removal of the tumour. However, the extent of the disease at diagnosis seems to be the most important factor that determines the outcome in the patient. A long patient's and/ or doctor's delay may allow an initially intraepithelial neoplastic condition to develop into frank invasive melanoma. The associated risk of regional and distant metastasis following the spread of subepithelial tumour cells into lymphatic and blood vessels depends on various clinicopathological factors.

Folberg and coworkers ${ }^{18}$ have emphasised the need of biopsying any suspicious pigmented lesion of the conjunctiva and of completely extirpating conditions which predispose to malignant melanoma. Localised melanomas are now generally treated by excisional biopsy, although in few centres primary radiotherapy has been used. ${ }^{22}{ }^{23}$ Lommatzsch has recently advocated local excision followed by $\beta$ irradiation $(\mathrm{Sr}-90 / \mathrm{Y}-90)$ or cryotherapy as the treatment of choice. ${ }^{24}$ In 1980 Jakobiec and colleagues ${ }^{4}$ first reported on their results of cryotherapy as an adjunct to debulking surgery. Cryotherapy of the conjunctiva is a conservative mode of treatment which aims at selective eradication of atypical intraepithelial melanocytes with minimal scarring of the underlying connective tissue. $^{25}$ Brownstein and coworkers ${ }^{25}$ recommended cryotherapy for the management of flat intraepithelial lesions but mentioned that cryotherapy usually results in locally recurrent disease because the source from which reepithelialisation of treated areas takes place is untreated conjunctiva which may harbour atypical melanocytes. In 1988 Jakobiec and colleagues $^{26}$ reported a high success rate for cryosurgery of PAM and of unifocal melanoma with or without PAM but observed a $45 \%$ rate of metastasis for patients with multinodular disease. However, extensive cryotherapy may cause serious side effects, including symblepharon, ptosis, motility disturbances, dry eye, loss of cilia, trichiasis iritis and posterior synechiae, corneal abrasion, opacification and vascularisation, and cataract. ${ }^{2526}$ Serious side effects have also been observed after $\beta$ irradiation. ${ }^{24}$

The management of more diffuse, proliferative primary acquired melanosis is difficult. After establishment of the diagnosis by formal biopsy, further treatment is indicated. The major benefit of a combination of surgery and adjunctive cryotherapy or $\beta$ irradiation is local control and potential cure of a neoplastic condition, while preserving useful vision and cosmesis. ${ }^{24} 25$ Apart from the various side effects listed above, there is a risk of recurrence by leaving diseased tissue in situ. Acquired melanosis sine pigmento is an amelanotic variant of PAM that easily escapes diagnosis and treatment until there is manifest nodular disease. ${ }^{26}{ }^{27}$ Reese $^{1}$ already pointed out that enucleation is contraindicated as it leaves potentially diseased conjunctiva which puts the patient at risk of developing metastasis. A well performed orbital exenteration is an effective way of eradicating tumour but this technique is mutilating, causes emotional distress, ${ }^{28}$ and leads to loss of vision. In extensive disease in which the eyelid margins are involved, a limited anterior lid splitting exenteration may be insufficient to eradicate all tumour, ${ }^{17}$ and a total exenteration should be considered. Jakobiec $e t a l^{4}$ pointed out that exenteration of orbital tissues is 'merely a matter of surgical convenience than of biologic necessity', since the conjunctival lymphatic drainage only takes place in the anterior part of the orbit. Wide conjunctivectomy is an alternative which often leads to the formation of symblepharon and decreased ocular motility. The shortage of conjunctiva and its resulting adverse effect on global function can be overcome by transplantation of full thickness mucosal grafts. These grafts may be harvested from the contralateral eye, or, when a bigger graft is required, from the inner mouth. The latter, however, tends to be thick and disfiguring and may mask tumour growth underneath for a long time.

To evaluate the controversial role of orbital exenteration in the management of malignant melanomas of the caruncle, we looked at outcome following exenteration in a group of 18 cases of caruncular melanomas. The poor survival despite orbital exenteration suggests that metastasis has already occurred at the time this treacherous tumour is treated. The fact that the caruncle is a skin derivative with a different anatomy from that of the conjunctiva may underlie the worsened prognosis for melanomas in this location. Orbital exenteration for a localised melanoma at the caruncle without evidence of multifocal areas of tumour or flat melanosis elsewhere seems an illogical procedure. Firstly, orbital exenteration results in a maximum nasal clearance of only $2 \mathrm{~mm}$, which may lead to incomplete resection despite such radical treatment. Secondly, the present study has shown that orbital exenteration is unlikely to alter the prognosis for survival when melanoma of the caruncle has invaded the subepithelial space. Therefore, it seems more appropriate to perform an excision biopsy for a localised caruncular melanoma. When the tumour displays medial extension, adjunctive external beam radiotherapy ${ }^{29}$ could be applied to the medial canthus to establish local control of the neoplasm and prevent further spread into the lacrimal apparatus, the nasal cavity, and paranasal sinuses. ${ }^{170}$ When there is obvious orbital extension of a localised caruncular melanoma, orbital exenteration may be indicated as a palliative procedure.

Whether scleral invasion detected in an exenteration specimen signifies an aggressive tumour behaviour with an intrinsic ability of the melanocytes to penetrate into dense tissues or merely reflects an advanced stage of the disease remains uncertain, despite the finding of an association between scleral invasion and relatively high mortality. When orbital invasion is seen on histological examination of the exenteration specimen (Fig 8), there is an increased likelihood of regional lymph node metastases and distant blood borne metastases. Folberg 
Figure 8 This photograph represents the exenteration specimen of the left orbit of a 49-year-old white woman showing diffuse primary acquired melanosis with atypia and a tumour mass in the upper fornix, composed of predominantly epithelioid cells. Note the $3.0 \times 0.8 \mathrm{~mm}$ melanoma nodule (arrow) between the sclera overlying the ciliary body and Tenon's capsule. Before exenteration in 1985, the patient had been treated by three excisional biopsies and one course of $\beta$ radiation ( $8000 \mathrm{cGy}$ ). The growth of tumour nodule deep to Tenon's capsule may have been assisted by previous surgery. In 1988 the patient developed a melanoma in the ipsilateral nasal cavity and maxillary sinus (haematoxylin and eosin, $\times 16)$.

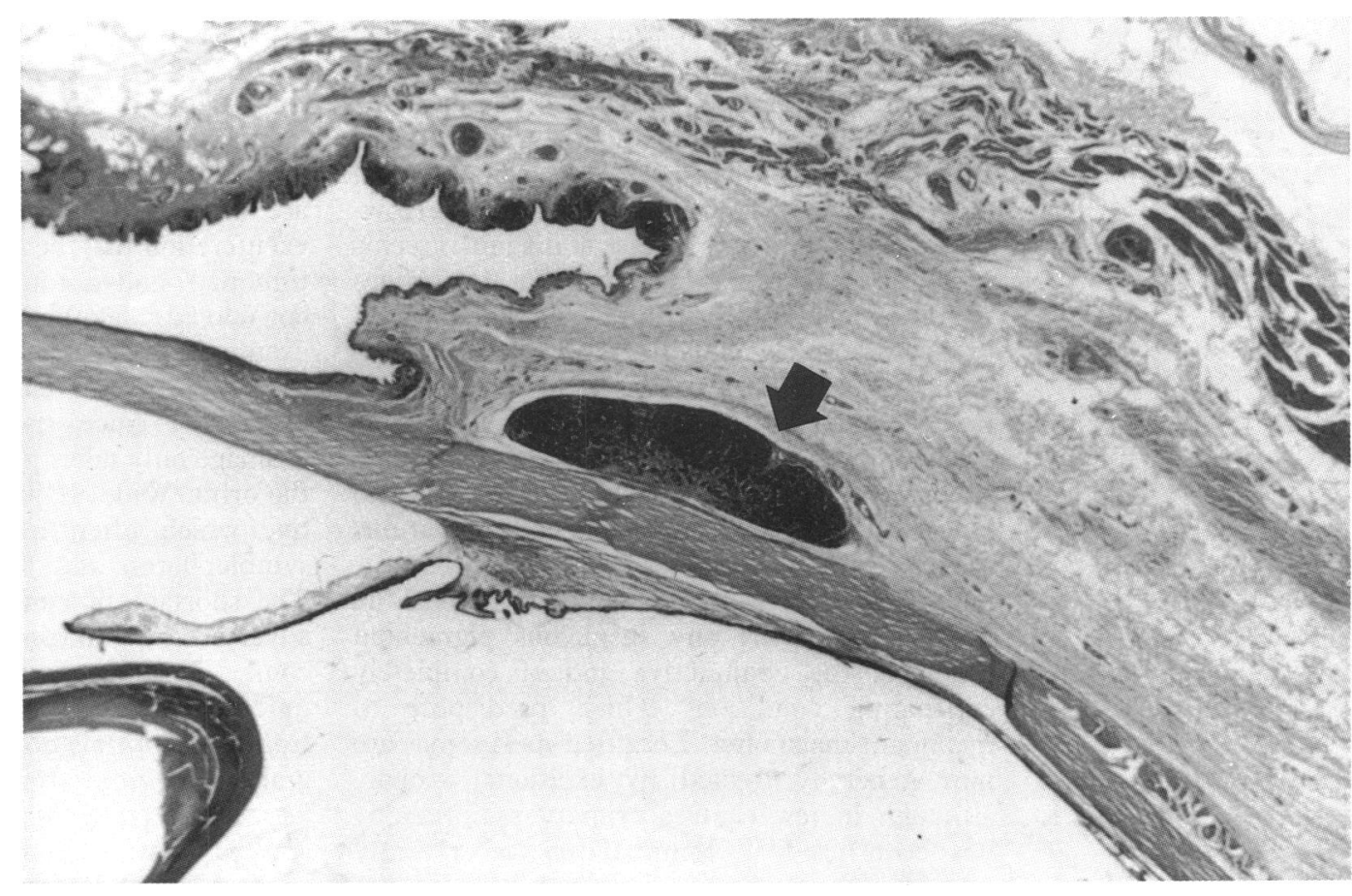

et $a l^{13}$ reported a study of 53 patients treated by exenteration for conjunctival melanoma. They found that $16(89 \%)$ of 18 patients with orbital invasion of melanoma developed metastatic disease, while $15(43 \%)$ of 35 patients without evidence of orbital extension of their melanoma experienced metastases.

It is questionable whether prophylactic irradiation or excision of the regional lymph nodes benefits the patient. While the disease free interval may be increased by such therapy, clinical experience in treating head and neck melanomas suggests that the survival rate is not influenced by prophylactic surgical or radiotherapeutic intervention. In conclusion, the findings in this study indicate that total eradication of conjunctival melanoma should be performed at an early stage. To achieve this, a combination of surgery and adjunctive cryotherapy or radiotherapy seems more appropriate than exenteration of the orbit which causes disfigurement and blindness. Orbital exenteration should be reserved as a palliative treatment for advanced stages of conjunctival melanomas that have entered an aggressive phase.

We thank Miss G Chrysanthopolou, the cancer follow up secretary at Moorfields Eye Hospital, who provided us with recent follow up information on the tumour status of patients who underwent exenteration. We would also like to thank the medical illustration department, Moorfields Eye Hospital and Mr Gerard de Graaf for their photographical assistance.

Dr A D A Paridaens was financially supported by the Dr F P Fischer Stichting, Utrecht, The Netherlands.

1 Reese AB. Precancerous and cancerous melanosis. In: Boniuk M, ed. Ocular and adnexal tumors. St Louis: Mosby, 1964 19-23.

2 Zimmerman LE. Discussion of pigmented tumors of the conjunctiva. In: Boniuk $M$, ed. Ocular and adnexal tumors. St Louis: Mosby, 1964: 24-48.

3 Jakobiec FA. Conjunctival melanoma. Unfinished business. Arch Ophthalmol 1980; 98: 1378-84.

4 Jakobiec FA, Brownstein S, Wilkinson RD, Khalil M, Cooper WC, Shibata HR. Combined surgery and cryotherapy for diffuse malignant melanoma of the conjunctiva. Arch diffuse malignant melanoma

5 Jakobiec FA, Folberg R, Iwamoto T. Clinicopathologic characteristics of premalignant and malignant melanocytic lesions of the conjunctiva. Ophthalmology 1989; 96: 146-66.

6 Kennedy RE. Indications and surgical techniques for orbital exenteration. Ophthalmology 1979; 86: 967-73.

7 Rendahl I. Does exenteratio orbitae improve the prognosis in orbital tumour? Acta Ophthalmol 1954; 32: 431-49.
8 Spaeth EB. Information learned from fifty years of orbita exenteration. Trans Ophthalmol Soc UK 1971; 91: 611-34.

9 Rathbun JE, Beard C, Quickert MH. Evaluation of 48 cases of orbital exenteration. Am F Ophthalmol 1971; 72: 191-9.

10 Naquin HA. Exenteration of the orbit. Arch Ophthalmol 1954; 51: $850-62$.

11 Bartley GB, Garrity JA, Waller RR, Henderson JW, Ilstrup DM. Orbital exentration and the Mayo Clinic, 1967-1986. Ophthalmology 1989; 96: 468-74.

12 Kersten RC, Tse DT, Anderson RL, Blodi FC. The role of orbital exenteration in choroidal melanoma with extrascleral extension. Ophthalmology 1985; 92: 436-43.

13 Folberg R, McLean IW, Zimmerman LE. Conjunctival melanosis and melanoma. Ophthalmology 1984; 91: 673-8.

14 Silvers DN, Jakobiec FA, Freeman TR, Lefkowitch JH, Elie RC. Melanoma of the conjunctiva: a clinicopathologic study. In: Jakobiec FA, ed. Ocular and adnexal tumors. Birmingham, AL: Aesculapius, 1978: 583-99.

15 Paridaens ADA, Minassian D, McCartney ACE, Hungerford JL. Prognostic factors in malignant melanoma of the conjunctiva: a clinico-pathological study of 256 cases. Submitted.

16 Folberg R, McLean IW. Primary acquired melanosis and melanoma of the conjunctiva: terminology, classification and biological behavior. Hum Pathol 1986; 17: 652-4.

17 Paridaens ADA, McCartney ACE, Lavelle RJ, Hungerford JL. Nasal and orbital recurrence of conjunctival melanoma 21 years after exenteration. Br $\mathcal{F}$ Ophthalmol 1992; 76: 21 years

18 Folberg R, McLean IW, Zimmerman LE. Primary acquired melanosis of the conjunctiva. Hum Pathol 1985; 16: 129-35.

19 Folberg R, McLean IW, Zimmerman LE. Malignan melanoma of the conjunctiva. Hum Pathol 1985; 16: 136-43.

20 Fuchs U, Kivela T, Liesto K, Tarkkanen A. Prognosis of conjunctival melanomas in relation to histopathological features. Brf Cancer 1989; 59: 261-7.

21 Stefani $\mathrm{FH}$. A prognostic index for patients with malignant melanoma of the conjunctiva. Graefes Arch Clin Exp Ophthalmol 1986; 224: 580-2.

22 Lederman M. Radiotherapy of malignant melanomata of the eye. Brf Radiol 1961; 34: 21-42.

23 Lommatzsch P. Beta irradiation of conjunctival melanomas. Trans Ophthalmol Soc UK 1977; 97: 378-80.

24 Lommatzsch PK, Lommatzsch RE, Kirsch I, Fuhrmann P. Therapeutic outcome of patients suffering from malignan melanomas of the conjunctiva. Br $\mathcal{F}$ Ophthalmol 1990; 74 615-9.

25 Brownstein S, Jakobiec FA, Wilkinson RD, Lombardo J Jackson W. Cryotherapy for precancerous melanosis (atypical melanocytic hyperplasia) of the conjunctiva. Arch Ophthalmol 1981; 99: 1224-32.

26 Jakobiec FA, Rini FJ, Fraunfelder FT, Brownstein S. Cryotherapy for conjunctival primary acquired melanosis and malignant melanoma. Ophthalmology 1988; 95: 1058-70.

27 Paridaens ADA, McCartney ACE, Hungerford JL. Multifocal amelanotic conjunctival melanoma and acquired melanosis amelanotic conjunctival melanoma and acquired

28 Hosein AM. Exenteration: the nursing approach. fOphthalmic Nurs Technol 1989; 8: 91-6.

29 Hykin PG, McCartney ACE, Plowman PN, Hungerford JL. Postenucleation orbital radiotherapy for the treatment of malignant melanoma of the choroid with extrascleral extension. BrF Ophthalmol 1990; 74: 36-9.

30 Robertson DM, Hungerford JL, McCartney ACE. Malignant melanomas of the conjunctiva, nasal cavity, and paranasa sinuses. Am $\mathcal{F}$ Ophthalmol 1989; 108: 440-2. 